\title{
The influence of lung volume reduction surgery on exercise in patients with COPD
}

\author{
T.E. Dolmage*, T.K. Waddell ${ }^{\#}$, F. Maltais ${ }^{\Uparrow}$, G.H. Guyatt ${ }^{+}$, T.R.J. Todd" ${ }^{\#}$ S. Keshavjee ${ }^{\#}$, S. van Rooy*, \\ B. Krip*, P. LeBlanc ${ }^{+}$, R.S. Goldstein*,\#
}

The influence of lung volume reduction surgery on exercise in patients with COPD. T.E. Dolmage, T.K. Waddell, F. Maltais, G.H. Guyatt, T.R.J. Todd, S. Keshavjee, S. van Rooy, B. Krip, P. LeBlanc, R.S. Goldstein. (C)ERS Journals Ltd 2004.

ABSTRACT: Although the influence of lung volume reduction surgery (LVRS) on incremental- and constant-power exercise is important in the evaluation of this procedure for patients with chronic obstructive pulmonary disease (COPD), it is rarely reported even in large randomised controlled trials.

This report describes 39 patients with severe COPD ((mean \pm SE) forced expiratory volume in one second $32 \pm 2 \%$ pred, functional residual capacity $195 \pm 6 \%$ pred) who participated in a randomised controlled trial of LVRS and who completed incremental exercise tests at 6 months as well as endurance tests (constant power of $25 \pm 1 \mathrm{~W}$ ) at 3,9 and 12 months.

Peak oxygen uptake $\left(V^{\prime} \mathrm{O}_{2}, \mathrm{pk}\right)$ was similar between the treatment $(\mathrm{n}=19)$ and control groups $(n=20)$ at baseline. After LVRS, the treatment group had a significantly greater $V^{\prime} \mathrm{O}_{2}$,pk (mean difference $\left.(95 \% \mathrm{CI}) 1.28(0.07-2.50) \mathrm{mL} \cdot \mathrm{kg} \cdot \mathrm{min}^{-1}\right)$ and power $(13(6-20) \mathrm{W})$. The treatment group achieved a significantly greater minute ventilation (7.1 (2.9-11.3) $\left.\mathrm{L} \cdot \mathrm{min}^{-1}\right)$ with a greater tidal volume $(0.16(0.04-0.28) \mathrm{L})$. Baseline endurance was similar between groups. After surgery, there were significant between-group differences in endurance time, which were maintained at 12 months $(7.3(3.9-10.8) \mathrm{min})$.

Lung volume reduction surgery is associated with an increase in exercise capacity and endurance, as compared with conventional medical treatment.

Eur Respir J 2004; 23: 269-274.

\begin{abstract}
*West Park Healthcare Centre, and ${ }^{*}$ the Lung Volume Reduction Surgery Clinic, University Health Network, University of Toronto, Toronto, "Hopital Laval, Sainte-Foy, Quebec, and ${ }^{+}$McMaster University Health Sciences Centre, Hamilton, Canada.
\end{abstract}

Correspondence: R.S. Goldstein, West Park Healthcare Centre, 82 Buttonwood Avenue, Toronto, Ontario, M6M 2J5 Canada.

Fax: 14162438947

E-mail: rgoldstein@westpark.org

Keywords: Chronic obstructive pulmonary disease, exercise, lung volume reduction surgery, prospective study, pulmonary gas exchange, randomised controlled trial

Received: June 172003

Accepted after revision: October 192003

This study was supported, in part, by the Physician's Services Incorporated Foundation (Ontario, Canada) and by West Park Healthcare Centre Foundation.
Chronic obstructive pulmonary disease (COPD) is characterised by expiratory flow limitation. During exercise, the increase in ventilation leads to an increase in end-expiratory lung volume (EELV). Breathing at higher lung volumes obliges the respiratory muscles to work against an increased elastic load, resulting in excessive dyspnoea and exercise intolerance in patients with COPD.

Lung volume reduction surgery (LVRS) has been identified as a method by which health-related quality of life can be increased for patients with COPD [1-5]. The decrease in hyperinflation and increase in lung elastic recoil increases expiratory flow, and should lead to a reduction in dynamic hyperinflation for any given ventilation. The reduced work of breathing decreases dyspnoea and improves exercise tolerance.

Although initial reports following LVRS noted improvements in exercise, these reports were from uncontrolled studies with varied designs and often with incomplete outcome measures. The few randomised controlled trials (RCT) of LVRS have provided very limited information on its effects on exercise capacity or endurance [2-5]. In a recent large RCT of 1,218 subjects [5], incremental exercise was used to categorise subjects into high or low capacity (peak power $(P \mathrm{pk})$ of 40 and $25 \mathrm{~W}$ for males and females, respectively) and improvement was defined arbitrarily as an increase in exercise capacity of $>10 \mathrm{~W}$. This study did not report the magnitude of improvement in exercise capacity or endurance. In one RCT in which physiological parameters were reported [2], the results were limited to 3 months after surgery. More detailed information regarding exercise capacity is highly relevant when considering surgery for this patient population, especially given the recently reported improvements in health status following LVRS $[4,5]$. The current paper reports the effect of LVRS on exercise, with repeated measures over 12 months, to identify whether subjects experienced a sustained effect of surgery, as compared with conventional medical management.

\section{Methods}

\section{Trial design}

The exercise measurements in this report were taken from an RCT of LVRS in which the primary outcome was healthrelated quality of life. The trial design has been described elsewhere [4]. In summary, enrolment criteria included: age $<75$ yrs; severe, stable COPD (forced expiratory volume in one second (FEV1) $<40 \%$ pred, FEV1/forced vital capacity $<0.7$ ), hyperinflation at total lung capacity (TLC) (TLC by plethysmograph $>120 \%$ pred) and gas trapping at TLC (TLC plethysmograph-TLC gas dilution $>1.5 \mathrm{~L}$ ); evidence of heterogeneity on a computerised tomogram or on a ventilation/perfusion scan. Subjects had to have quit smoking for $>6$ months and be receiving optimal pharmacological management. Pulmonary hypertension, associated conditions that would limit exercise tolerance and recent exacerbations were all exclusion criteria. Subjects were asked to sign informed 
consent (University of Toronto Ethics Review Board, Toronto, Canada). After a 6-week programme of rehabilitation [6], subjects were randomised (concealed randomisation) to surgical or medical therapy. Incremental exercise and constant-power exercise were completed before randomisation and at followup, after 6 months for incremental exercise and after 3,9 and 12 months for constant-power exercise. All staff responsible for outcome measures were blinded as to the subject's group.

\section{Surgery}

Surgery was performed by video-assisted thoracoscopic surgery or, less often, by median sternotomy, the extent and location of the resection being determined by the surgeon. At surgery, $20-30 \%$ of the lung volume was removed. Mechanical staplers and bovine pericardium were used routinely and pleural tents were used occasionally. Subjects were extubated in the operating room immediately after regaining consciousness. They subsequently remained in the surgical step-down unit until they were clinically stable, after which they were transferred to the thoracic surgical ward. Once stable, subjects were offered a brief (1-2 weeks) period of rehabilitation or discharged directly home.

\section{Pulmonary function and exercise testing}

Full pulmonary function measures were completed at baseline [7-9]. Primary outcomes were the peak oxygen uptake $\left(V^{\prime} \mathrm{O}_{2}, \mathrm{pk}\right)$ and $P$ pk during the incremental-exercise test, as well as the endurance time ( $t$ limit) of the submaximal constantpower exercise tests. Secondary outcomes were parameters measured at the end of the incremental exercise, including peak minute ventilation $\left(V^{\prime} \mathrm{E}, \mathrm{pk}\right)$, tidal volume $(V \mathrm{~T}, \mathrm{pk})$, frequency of breathing $(\mathrm{fb}, \mathrm{pk})$ and dyspnoea using a modified Borg scale $[10,11]$.

For every exercise test, subjects were requested to adhere to their usual medical regimens but not to eat for $2 \mathrm{~h}$ before the test and not to drink caffeinated beverages for $12 \mathrm{~h}$ before the test. Exercise tests were carried out in a standardised manner [12] with an electrically braked cycle ergometer (Collins CPX Bike model 3070; Warren E. Collins, Braintree, MA, USA). The test was discontinued if any cardiovascular instability (hypertension, hypotension or electrocardiographic changes) was observed. The subjects wore nose clips and breathed through the mouthpiece of a calibrated screen pneumotachograph (Collins/Cybermedic model 003500; Warren E. Collins) that was located $5 \mathrm{~cm}$ from the mouth. The pneumotachograph calibration procedure conformed to American Thoracic Society standards [8]. The accuracy of the pneumotachograph was verified after each exercise test. All subjects breathed room air. After at least $1 \mathrm{~min}$ of breathing through the mouthpiece, the subject started unloaded cycling. During incremental exercise tests the load was increased (1 W increments at a rate of $5 \mathrm{~W} \cdot \mathrm{min}^{-1}$ ) until the subject reached symptom limitation $(P \mathrm{pk})$. The rate of increase was designed to induce symptom limitation within $\sim 10 \mathrm{~min}$. Peak cardiopulmonary parameters were averaged over the last $30 \mathrm{~s}$ of exercise. Cardiopulmonary parameters were also determined at isopower, defined as the greatest power common to both baseline and follow-up incremental exercise tests.

During constant-power exercise tests the load was increased immediately to $70 \%$ of the $P$ pk achieved on the baseline incremental test. This targeted intensity provided a symptomlimited exercise duration (tlimit) that was sufficiently brief to remain sensitive to change yet avoid the likelihood of prolonged exercise $(20 \mathrm{~min})$ being limited by motivation or intolerance of the breathing apparatus.

\section{Inspiratory capacity}

Inspiratory capacity (IC) has been identified as a useful approach for evaluating dynamic hyperinflation in COPD [13, 14]. This measurement became available to the current authors partway through this study. After validating the measurement and evaluating its repeatability [15], the authors decided to include IC measurements during the incremental exercise test in all remaining subjects. IC was measured at rest and randomly at 1-3 min intervals during exercise. The manoeuvres were unscheduled to avoid the possibility of the subjects changing their pattern of breathing in anticipation of the prompt. EELV was calculated from the difference between the IC and the TLC by plethysmograph. Serial EELV measures were expressed as a linear function of ventilation. The slope summarised the entire response with a positive slope indicating dynamic hyperinflation.

\section{Analysis}

Mean values for each variable were calculated and expressed as mean \pm SE, as well as mean $(95 \%$ confidence intervals (CI)) unless otherwise stated. All variables were analysed using a mixed-effects model. For each variable from the incremental test, a t-test was conducted using the baseline value as a covariate. For each variable from the constantpower test, a repeated measures analysis of variance was conducted using the baseline value as a covariate. The effect of time, treatment and the interaction between the two were determined. To provide an estimate of the magnitude and precision of the determination of the effect of treatment, the mean difference between treatment and control at the same follow-up was used and adjusted for the baseline score. A 95\% CI was calculated around this difference.

To demonstrate the effect of LVRS on breathing during exercise, each respiratory variable $\left(V^{\prime} \mathrm{E}, \mathrm{pk}, V_{\mathrm{T}, \mathrm{pk},} f \mathrm{~b}, \mathrm{pk}\right.$ and arterial oxygen saturation measured by pulse oximetry $\left.\left(\mathrm{Sp}, \mathrm{O}_{2}\right)\right)$ was analysed as follows. For each variable, each subject's constant-power exercise response was divided into 10 uniformly spaced intervals and expressed as a percentage of its respective peak exercise value. Each variable was adjusted for baseline values and averaged to produce an average exercise waveform. The waveform was then converted to absolute values by multiplying it by the respective end exercise mean value. Each averaged respiratory variable was plotted against the averaged exercise time. Constant-power exercise variables were also compared at the same exercise time (isotime) determined by the subject's shortest exercise time during any constant-power test.

\section{Results}

\section{Enrolment}

A total of 55 subjects were randomised after rehabilitation (28 surgery and 27 controls). Details of nonparticipating and ineligible subjects have been described elsewhere [4]. Subjects assigned to the treatment and control groups had similar baseline pulmonary function.

\section{Deaths and complications}

In the surgical group there were two deaths within 30 days of surgery and a further two deaths within the 12-month follow-up period. In the control group, one subject died of respiratory failure 117 days post-randomisation. There were 
four serious complications in the treatment group including prolonged ventilation (two), significant bleeding (one) and sternal dehiscence (one), and one serious complication (cerebrovascular accident) in the control group.

\section{Exercise capacity}

A total of 39 subjects (19 subjects from the treatment group and 20 control subjects) completed incremental exercise tests at 6 months. Of the 16 subjects who did not complete followup incremental exercise tests, three died within 6 months (two treatment and one control), two sustained complications (one treatment subject required prolonged ventilation and one control subject sustained an acute cerebrovascular accident). The remaining 11 subjects (six surgical and five control) declined follow-up exercise testing for a variety of reasons (acute exacerbations, time commitments, travel requirements or disinterest as they didn't enjoy exercise testing). Subjects were aware that they could decline any measure at any time without this affecting their medical management. Those with incomplete exercise-outcome measures did not differ in age, height, weight, pulmonary function or resting blood gases from those who completed follow-up exercise tests (table 1).

At baseline, all subjects completed their incremental exercise test with dyspnoea scores that varied from somewhat severe $($ dyspnoea $=4)$ to maximal breathlessness (dyspnoea=10). Their exercise capacity was reduced ( $P$ pk $27 \pm 2 \%$ pred). All subjects demonstrated characteristics of ventilatory limitation ( $V^{\prime}$ E,pk $103 \pm 4 \%$ maximum voluntary ventilation pred and $\mathrm{Sp}, \mathrm{O}_{2} 86 \pm 1 \%$ ) and an inability to reach maximum heart rate $(75 \pm 2 \%$ pred). However, heart rate was elevated for a given submaximal oxygen uptake. All subjects in whom the IC manoeuvre was measured showed dynamic hyperinflation, the rate of their increasing EELV ranged $28-131 \mathrm{~mL}$ for every $1 \mathrm{~L} \cdot \mathrm{min}^{-1}$ increase in $V^{\prime} \mathrm{E}, \mathrm{pk}$.

\section{Outcomes}

The results from the incremental exercise test at 6-month follow-up are presented in table 2. There was a significant treatment effect of LVRS on $V^{\prime} \mathrm{O}_{2}$,pk (difference 1.28 $(0.07-2.50) \mathrm{mL} \cdot \mathrm{kg}^{-1} \cdot \mathrm{min}^{-1} ; \mathrm{p}=0.04$ ) and $P \mathrm{pk}$ (difference 13 $(6-20) \mathrm{W} ; \mathrm{p}=0.0003)$. The treatment group had a significantly greater $V^{\prime} \mathrm{E}, \mathrm{pk}$ (difference $\left.7.1(2.9-11.3) \mathrm{L} \cdot \mathrm{min}^{-1} ; \mathrm{p}<0.002\right)$,
Table 1.-Baseline pulmonary function among subjects who completed exercise tests

\begin{tabular}{|c|c|c|}
\hline \multirow[t]{2}{*}{ Parameter } & \multicolumn{2}{|c|}{ Exercise tests } \\
\hline & Completed & Incomplete \\
\hline Subjects $n \mathrm{M} / \mathrm{F}$ & $24 / 15$ & $10 / 6$ \\
\hline Age yrs & $64 \pm 1$ & $67 \pm 1$ \\
\hline Height $\mathrm{cm}$ & $167 \pm 2$ & $170 \pm 3$ \\
\hline Weight kg & $68 \pm 2$ & $65 \pm 4$ \\
\hline TLC $\%$ pred & $147 \pm 4$ & $141 \pm 3$ \\
\hline FRC $\%$ pred & $198 \pm 6$ & $189 \pm 5$ \\
\hline RV \% pred & $241 \pm 10$ & $238 \pm 11$ \\
\hline FVC L & $2.4 \pm 0.1$ & $2.7 \pm 0.2$ \\
\hline FVC $\%$ pred & $71 \pm 3$ & $77 \pm 5$ \\
\hline FEV1 L & $0.7 \pm 0.1$ & $0.8 \pm 0.1$ \\
\hline FEV1 \% pred & $32 \pm 2$ & $32 \pm 2$ \\
\hline FEV $1 / \mathrm{FVC} \%$ & $33 \pm 2$ & $30 \pm 2$ \\
\hline VA $\%$ pred & $73 \pm 3$ & $72 \pm 4$ \\
\hline$D \mathrm{~L}, \mathrm{CO} \%$ pred & $37 \pm 2$ & $32 \pm 3$ \\
\hline $\mathrm{Pa}, \mathrm{O}_{2} \mathrm{mmHg}$ & $70 \pm 2$ & $69 \pm 2$ \\
\hline $\mathrm{Pa}_{1} \mathrm{CO}_{2} \mathrm{mmHg}$ & $44 \pm 1$ & $42 \pm 1$ \\
\hline $\mathrm{Sa}_{\mathrm{a}, \mathrm{O}_{2}} \%$ & $93 \pm 1$ & $93 \pm 1$ \\
\hline
\end{tabular}

M: male; F: female; TLC: total lung capacity; FRC: functional residual capacity; RV: residual volume; FVC: forced vital capacity; FEV1: forced expiratory volume in one second; $V A$ : alveolar volume by helium dilution; $D \mathrm{~L}, \mathrm{CO}$ : carbon monoxide diffusing capacity of the lung; $\mathrm{Pa}, \mathrm{O}_{2}$ : arterial oxygen tension; $\mathrm{Pa}, \mathrm{CO}_{2}$ : arterial carbon dioxide tension; $\mathrm{Sa}, \mathrm{O}_{2}$ : arterial oxygen saturation.

as a result of a significantly greater $V$ T,pk (difference 0.16 $(0.04-0.28) \mathrm{L} ; \mathrm{p}<0.01)$ and similar $f \mathrm{~b}, \mathrm{pk}$. There was a trend for the treatment group to have a greater $S \mathrm{p}, \mathrm{O}_{2}$ at the end of exercise (difference $3(0-6) \% ; p=0.06)$. Forward stepwise regression of ventilatory parameters (including $\mathrm{Sp}, \mathrm{O}_{2}$ ) at peak exercise and isopower revealed that the dependent variable, change in $V^{\prime} \mathrm{O}_{2}$, pk, could be predicted from the independent variable, change in $V^{\prime} \mathrm{E}$,pk (adjusted $\mathrm{R}^{2}=0.50 ; \mathrm{p}=0.001$ ). The other variables did not significantly add to the ability to predict the change in $V^{\prime} \mathrm{O}_{2}$,pk.

The results of the constant-power test are summarised in figure 1. tlimit was similar at baseline between the treatment and control group (6.9 (4.5-9.3) versus 6.6 (4.7-8.4) min, respectively), and there was a significant interaction between treatment and time with significant between-group differences being maintained through 12 months (7.3 (3.9-10.8) min;

Table 2. - Peak incremental exercise results following lung volume reduction surgery

\begin{tabular}{|c|c|c|c|c|c|}
\hline & \multicolumn{2}{|c|}{ Baseline } & \multicolumn{2}{|c|}{6 months after baseline } & \multirow[t]{2}{*}{ Difference } \\
\hline & Treatment & Control & Treatment & Control & \\
\hline Subjects n & 19 & 20 & 19 & 20 & \\
\hline PowerW & $37 \pm 2$ & $34 \pm 3$ & $44 \pm 2$ & $31 \pm 2$ & $13^{*}$ \\
\hline$V^{\prime} \mathrm{O}_{2}, \mathrm{pk} \mathrm{L} \cdot \min ^{-1}$ & $0.47 \pm 0.04$ & $0.47 \pm 0.04$ & $0.55 \pm 0.03$ & $0.49 \pm 0.03$ & 0.07 \\
\hline$V^{\prime} \mathrm{O}_{2}, \mathrm{pk} \mathrm{mL} \cdot \mathrm{kg}^{-1} \cdot \mathrm{min}^{-1}$ & $7.60 \pm 0.54$ & $6.60 \pm 0.46$ & $8.25 \pm 0.44$ & $6.98 \pm 0.39$ & $1.28 *$ \\
\hline$V^{\prime} \mathrm{E}, \mathrm{pk} \mathrm{L} \cdot \mathrm{min}^{-1}$ & $26.7 \pm 2.3$ & $21.9 \pm 1.4$ & $31.1 \pm 1.5$ & $24.0 \pm 1.4$ & $7.1^{*}$ \\
\hline$V T, p k \mathrm{~L}$ & $0.81 \pm 0.07$ & $0.79 \pm 0.06$ & $0.99 \pm 0.04$ & $0.83 \pm 0.04$ & $0.16^{*}$ \\
\hline$f \mathrm{~b}, \mathrm{pk} \min ^{-1}$ & $31 \pm 2$ & $29 \pm 2$ & $30 \pm 1$ & $29 \pm 1$ & 1 \\
\hline HR $\min ^{-1}$ & $121 \pm 3$ & $116 \pm 4$ & $125 \pm 2$ & $123 \pm 2$ & 2 \\
\hline $\mathrm{Sp}, \mathrm{O}_{2} \%$ & $87 \pm 1$ & $86 \pm 1$ & $89 \pm 1$ & $86 \pm 1$ & $3^{\pi}$ \\
\hline$V^{\prime} \mathrm{E}, \mathrm{pk} / V^{\prime} \mathrm{CO}_{2}$ & $52 \pm 2$ & $48 \pm 3$ & $49 \pm 2$ & $47 \pm 1$ & 3 \\
\hline Dyspnoea Borg & $7.4 \pm 0.5$ & $7.1 \pm 0.5$ & $6.2 \pm 0.5$ & $7.2 \pm 0.5$ & -1.1 \\
\hline Leg effort Borg & $5.4 \pm 0.6$ & $5.3 \pm 0.7$ & $5.7 \pm 0.5$ & $4.8 \pm 0.5$ & 0.9 \\
\hline
\end{tabular}

Follow-up measures are least-squared means adjusted for baseline measure. $V^{\prime} \mathrm{O}_{2}$,pk: peak oxygen uptake; $V^{\prime} \mathrm{E}$,pk: peak minute ventilation; $V^{\prime} \mathrm{T}$,pk: peak tidal volume; $f$ b,pk: peak frequency of breathing; $\mathrm{HR}$ : heart rate; $\mathrm{Sp}_{2} \mathrm{O}_{2}$ : arterial oxygen saturation measured by pulse oximetry; $V^{\prime} \mathrm{CO}$ : arterial carbon dioxide tension; *: $\mathrm{p}<0.05$ baseline-adjusted difference between groups 6 months post-baseline; $\uparrow$ : trend to a significant baseline-adjusted difference between groups 6 months post-baseline $(\mathrm{p}=0.06)$. 


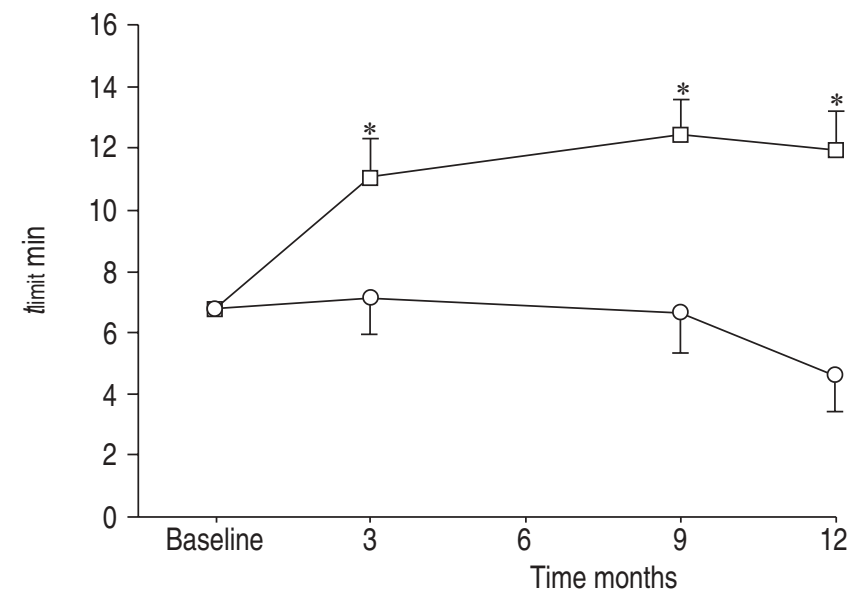

Fig. 1. - Endurance time of constant-power exercise ( $t$ limit) for the treatment $(\square)$ and control $(\bigcirc)$ groups at baseline, and 3, 9 and 12 months after randomisation. Values at follow-up are baseline-adjusted least square mean. *: p<0.05 baseline-adjusted difference between groups.

$p<0.0001)$. There was a significant treatment effect on endexercise $V_{\mathrm{T}}$ with a significant difference between groups at 3 months (difference $0.16(0.03-0.30) \mathrm{L} ; \mathrm{p}<0.02)$. The LVRS group had a significantly greater end-exercise $\mathrm{Sp}, \mathrm{O}_{2}$ (difference $3(0-6) \% ; \mathrm{p}=0.03$ ) and resting heart rate (difference -11 $(-20-2)$ beats $\left.\cdot \mathrm{min}^{-1} ; \mathrm{p}=0.02\right)$ at 12 months. Both groups showed similar increases in ventilation with time during constant-power exercise. The pattern of breathing changed 3 months after surgery to reflect a lower frequency and higher $V$ T among the surgical group (fig. 2). This change became less evident during follow-up measures at 9 and 12 months. At isotime (table 3), between-group differences reflected a greater $V_{\mathrm{T}}($ difference $0.15(0-0.30) \mathrm{L} ; \mathrm{p}<0.05)$ and a reduced respiratory frequency (difference $\left.-6(-11-1) \mathrm{min}^{-1} ; \mathrm{p}=0.03\right)$ at 3 months. These differences were not significant at 9 and 12 months. Between-group differences in $\mathrm{Sp}, \mathrm{O}_{2}$ were significant at 3 (difference $4(1-7) \% ; \mathrm{p}=0.02$ ) and 12 months (difference 4 $(1-7) ; \mathrm{p}=0.008)$.

\section{Inspiratory capacity}

IC was measured during exercise at baseline and at 6 months in 12 subjects. The average $V_{\mathrm{T}}$ responses during exercise are shown in figure 3. The change from baseline in the slope of the EELV is shown in figure 4. In three out of six treatment subjects the rate of increase in EELV diminished, exceeding the difference expected due to the variability of the measure (repeatability). In the remaining three subjects, the rate of increase in EELV remained constant and did not exceed the established measurements of repeatability [15]. In the six control subjects, the rate of increase of EELV during
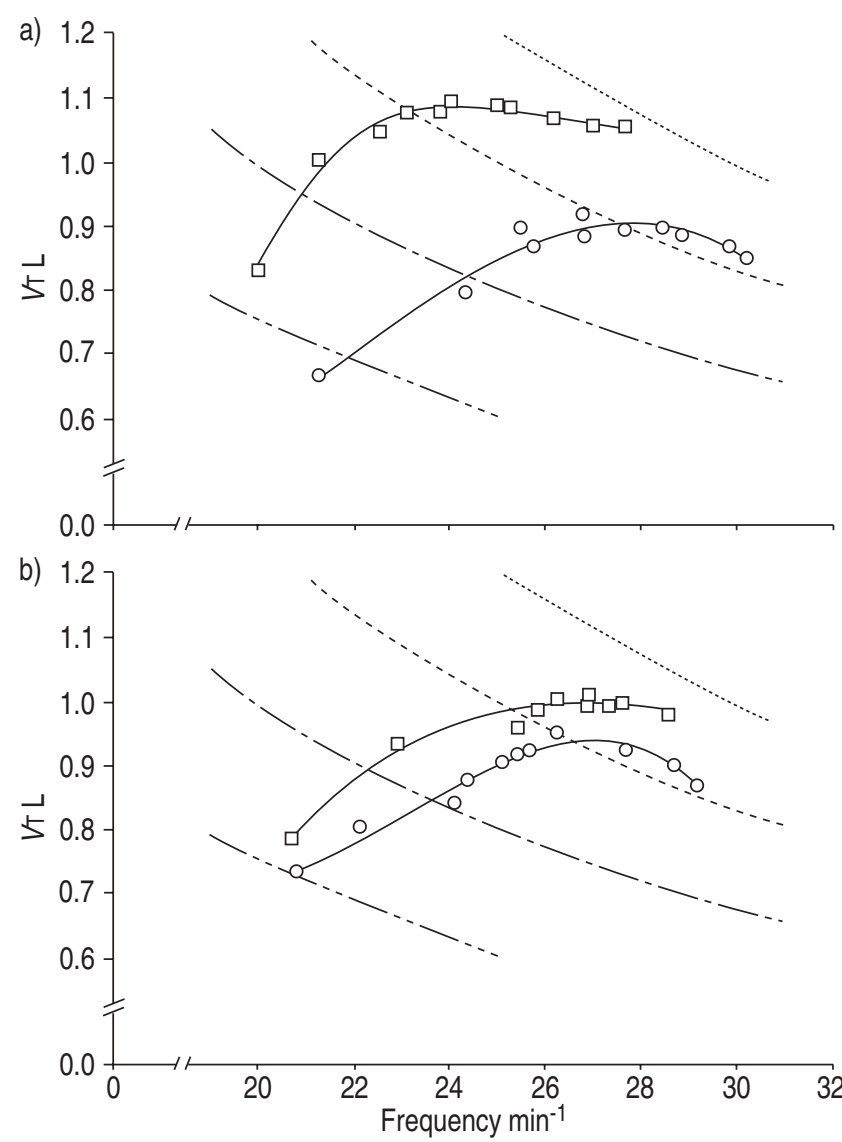

Fig. 2. - Pattern of breathing during constant-power exercise test for the treatment $(\square)$ and the control $(\bigcirc)$ groups at 3 (a) and 12 (b) months after randomisation. Isopleths indicate points of equal ventilation for $30(\cdots \cdots \cdots), 25(----), 20\left(--_{-}\right)$and $15\left(-{ }_{-}\right)$ $\mathrm{L} \cdot \mathrm{min}^{-1}$. Note the differences between the two groups in breathing frequency and tidal volume for any given ventilatory isopleth. The differences at 3 months are still present but diminished at 12 months.

exercise remained the same (four subjects) or increased (two subjects). At 6 months, the rate of increase of EELV during exercise was $36 \pm 8 \mathrm{~mL} \cdot \mathrm{min} \cdot \mathrm{L}^{-1}$ for the post-surgical subjects and $71 \pm 16 \mathrm{~mL} \cdot \mathrm{min} \cdot \mathrm{L}^{-1}$ for the control subjects. The baselinecorrected between-group difference at 6 months was 24 (5-53) $\mathrm{mL} \cdot \min \cdot \mathrm{L}^{-1}(\mathrm{p}=0.09)$. The statistical power was 0.40 with an alpha of 0.05 .

\section{Discussion}

Given the associated surgical risks, as well as healthcare costs [5], it is important to demonstrate that LVRS improves

Table 3. - Ventilatory parameters at isotime of constant-power exercise

\begin{tabular}{|c|c|c|c|c|c|c|c|c|}
\hline & \multicolumn{2}{|c|}{ Baseline } & \multicolumn{2}{|c|}{3 Months } & \multicolumn{2}{|c|}{9 Months } & \multicolumn{2}{|c|}{12 Months } \\
\hline & Treatment & Control & Treatment & Control & Treatment & Control & Treatment & Control \\
\hline$V^{\prime} \mathrm{E} \mathrm{L} \cdot \mathrm{min}^{-1}$ & $26.5 \pm 2.8$ & $21.8 \pm 1.9$ & $24.8 \pm 1.2$ & $25.3 \pm 1.1$ & $24.3 \pm 1.4$ & $23.7 \pm 1.2$ & $24.6 \pm 1.2$ & $25.4 \pm 1.1$ \\
\hline$V \mathrm{~T} \mathrm{~L}$ & $0.85 \pm 0.07$ & $0.85 \pm 0.07$ & $1.07 * \pm 0.05$ & $0.92 \pm 0.05$ & $1.04 \pm 0.07$ & $0.97 \pm 0.05$ & $1.02 \pm 0.06$ & $0.93 \pm 0.05$ \\
\hline$f \mathrm{~b} \min ^{-1}$ & $31 \pm 2$ & $26 \pm 2$ & $23 * \pm 2$ & $29 \pm 2$ & $24 \pm 2$ & $26 \pm 2$ & $25 \pm 2$ & $28 \pm 2$ \\
\hline $\mathrm{Sp}, \mathrm{O}_{2} \%$ & $87 \pm 2$ & $89 \pm 1$ & $92 * \pm 1$ & $88 \pm 1$ & $92 \pm 1$ & $89 \pm 1$ & $91 * \pm 1$ & $86 \pm 1$ \\
\hline
\end{tabular}

Follow-up measures are least-squared means adjusted for baseline measure. $V^{\prime} \mathrm{E}$ : minute ventilation; $V \mathrm{~T}$ : tidal volume; $f \mathrm{~b}$ : frequency of breathing; $S \mathrm{p}, \mathrm{O}_{2}$ : arterial oxygen saturation as measured by pulse oximetry. ${ }^{*}: \mathrm{p}<0.05$ baseline-adjusted difference between groups. 
exercise in patients with COPD. In the current study, the authors have presented the effects of LVRS on incremental exercise and constant-power exercise. The increased exercise endurance and associated physiological changes among the treatment group were sustained 1 yr after surgery.

$V^{\prime} \mathrm{O}_{2}$,pk is an excellent index of exercise capacity and is used to identify cardiopulmonary exercise limitations [16]. The severe cardiopulmonary limitations of the COPD patients enrolled were reflected in their low baseline $V^{\prime} \mathrm{O}_{2}$,pk. These observations extend those reported in uncontrolled studies, although the latter studies began with higher mean baseline values for $V^{\prime} \mathrm{O}_{2}, \mathrm{pk} \quad\left(9.7-14.6 \mathrm{~mL} \cdot \mathrm{kg}^{-1} \cdot \mathrm{min}^{-1}\right) \quad[2, \quad 17-23]$ compared with $6.9 \mathrm{~mL} \cdot \mathrm{kg}^{-1} \cdot \mathrm{min}^{-1}$ in the present study. The results presented in the present study also characterise the improvement in more precise terms than an arbitrary $10-\mathrm{W}$ change in incremental exercise reported recently in a large RCT of LVRS [16]. Six months after surgery, $P$ pk increased by $37 \%$ and $V^{\prime} \mathrm{O}_{2}$,pk increased by $18 \%$ with insignificant changes in these variables among control subjects.

Patients with severe COPD have already lost much of their cardiopulmonary reserve, so that a subsequent small change in cardiopulmonary capacity will have a large effect on functional capacity. After LVRS, there was a substantial $(75 \%)$ increase in constant-power exercise endurance (functional capacity), which was sustained at 12 months. The measured improvements in exercise would likely permit improvements in functional capacity in keeping with reported
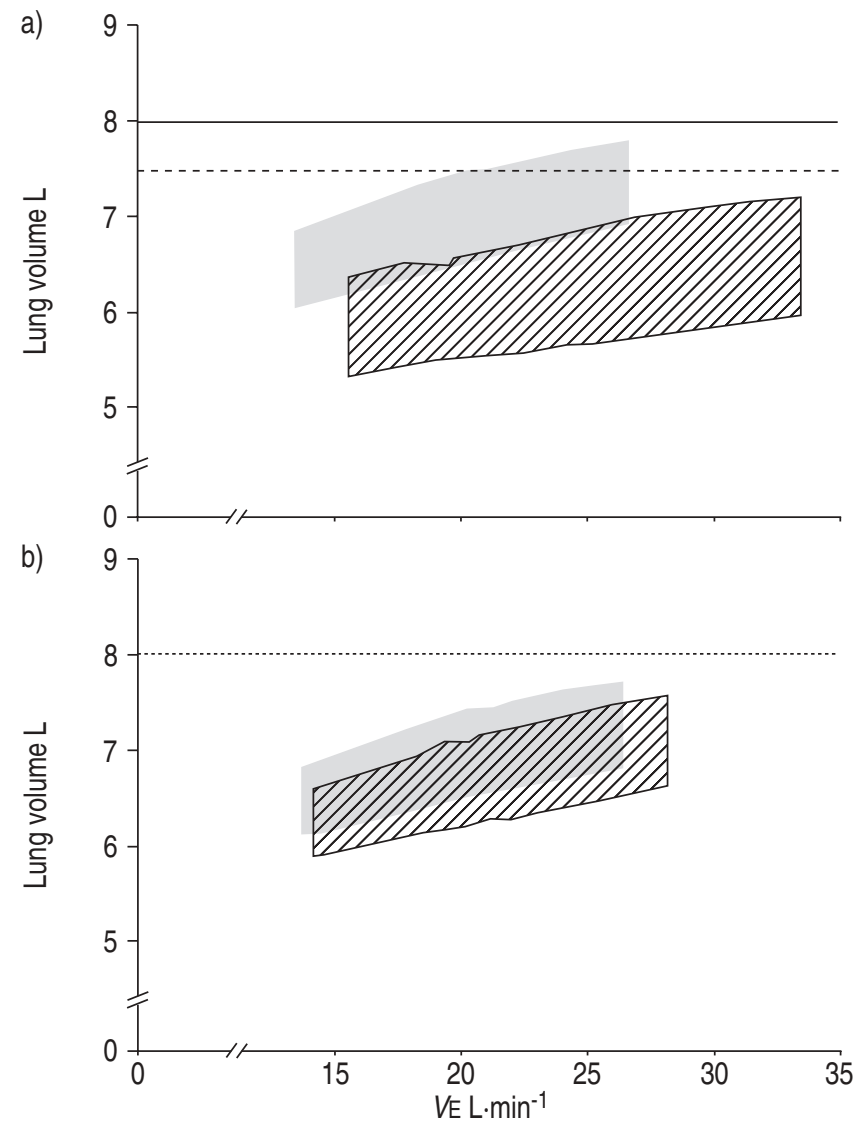

Fig. 3. - The baseline reference tidal volume $(V \mathrm{~T} ; \square)$ and $V \mathrm{~T}$ at 6 months $(\mathbb{\mathbb { N }})$ during incremental exercise for the treatment (a) and control (b) groups. End-inspiratory lung volumes (EILV; top border of areas) and end-expiratory lung volumes (EELV; bottom border of areas) are shown. The positive slope of the EELV indicates the presence of dynamic hyperinflation. - : total lung capacity (TLC) at baseline; ----: TLC post-surgery; ..... TLC baseline and post-randomisation. improvements in health-related quality of life [3-5]. The initial increase in exercise performance did not increase further over the subsequent 9 months. This highlights an opportunity for further improvements in exercise following LVRS if patients are encouraged to maintain an exercise programme after surgery. In contrast, exercise performance declined among control subjects. Given that control subjects were offered surgery at 12 months, the authors can only speculate regarding the duration of benefit following LVRS, although previous reports have suggested a gradual diminution of benefit over 24 months [5, 24].

An explanatory mixed-effects model was used in this study, which included all subjects completing at least one exercise test during follow-up, excluding only subjects missing baseline or all follow-up exercise tests. Two subjects from the treatment group and one from the control group were excluded due to death. The authors chose not to arbitrarily assign values to missing data to avoid confounding the physiological measures. While the physiological status of subjects who refused follow-up (five control and six treatment) is unknown, subjects excluded from the analysis were typical and representative of the subjects eligible for the study.

The increase in $V_{\mathrm{T}}$,pk and $V^{\prime} \mathrm{E}, \mathrm{pk}$ were seen only in the treatment group and were therefore attributable to LVRS. These changes in breathing pattern were most evident at 3 months with a gradual diminution in $\mathrm{Vt}$ and increase in frequency over the subsequent 9 months. $\mathrm{Sp}, \mathrm{O}_{2}$ also improved following surgery. This observation was unavailable in two other RCTs of LVRS, as in these trials oxygen was administered during all exercise tests $[2,5]$.

Mechanical changes following surgery include a decrease in resting EELV and an increase in inspiratory reserve volume $[2,17-19,22,25,26]$. Measurement of IC can be used to quantify dynamic hyperinflation from the EELV at rest and during exercise $[13,14]$. In the 12 subjects in whom IC was measured during baseline, the characteristic rise in EELV with exercise was noted [15]. Following LVRS this rise was reduced. Although the small sample size prevented sufficient power to establish statistical significance, the authors believe this observation to be clinically relevant and worthy of further study.

This randomised controlled trial demonstrated improvements in exercise capacity and constant-power endurance following lung volume reduction surgery in stable subjects

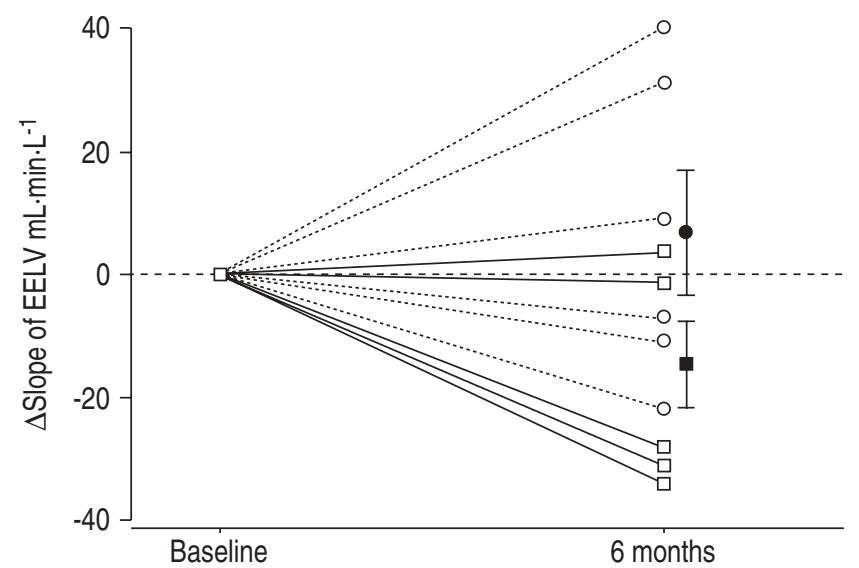

Fig. 4. - The change from baseline, during incremental exercise, in the slope of the end-expiratory lung volume (EELV). Negative values indicate reduced dynamic hyperinflation. Individual values for both the treatment $(\square)$ and control $(\bigcirc)$ groups are shown. The mean \pm SE change for the treatment $(\square)$ and control (O) groups are shown to the right of the individual values. 
with severe chronic obstructive pulmonary disease. These improvements were associated with improvements in the pattern of breathing and oxyhaemoglobin saturation that were maintained 12 months after surgery. These observations are in keeping with and supportive of the reported improvements in health status following lung volume reduction surgery [3-5].

\section{References}

1. Cooper JD, Trulock EP, Triantafillou AN, et al. Bilateral pneumectomy (volume reduction) for chronic obstructive pulmonary disease. J Thorac Cardiovasc Surg 1995; 109: 106-119.

2. Criner GJ, Cordova FC, Furukawa S, et al. Prospective randomized trial comparing bilateral lung volume reduction surgery to pulmonary rehabilitation in severe chronic obstructive pulmonary disease. Am J Respir Crit Care Med 1999; 160: 2018-2027.

3. Geddes D, Davies M, Koyama H, et al. Effect of lungvolume-reduction surgery in patients with severe emphysema. $N$ Engl J Med 2000; 343: 239-245.

4. Goldstein RS, Todd TR, Guyatt G, et al. Influence of lung volume reduction surgery (LVRS) on health related quality of life in patients with chronic obstructive pulmonary disease. Thorax 2003; 58: 405-410.

5. Fishman A, Martinez F, Naunheim K, et al. A randomized trial comparing lung-volume-reduction surgery with medical therapy for severe emphysema. N Engl J Med 2003; 348: 2059-2073.

6. Goldstein RS, Gort EH, Stubbing D, Avendano MA, Guyatt GH. Randomised controlled trial of respiratory rehabilitation. Lancet 1994; 344: 1394-1397.

7. American Thoracic Society. Lung function testing: selection of reference values and interpretative strategies. American Thoracic Society. Am Rev Respir Dis 1991; 144: 1202-1218.

8. American Thoracic Society. Standardization of Spirometry, 1994 Update. American Thoracic Society. Am J Respir Crit Care Med 1995; 152: 1107-1136.

9. American Thoracic Society. American Thoracic Society. Single-breath carbon monoxide diffusing capacity (transfer factor). Recommendations for a standard technique-1995 update. Am J Respir Crit Care Med 1995; 152: 2185-2198.

10. Borg G. Perceived exertion as an indicator of somatic stress. Scand J Rehabil Med 1970; 2: 92-98.

11. Borg GA. Psychophysical bases of perceived exertion. Med Sci Sports Exerc 1982; 14: 377-381.

12. Jones NL. Clinical Exercise Testing. 3rd ed. Philadelphia, PA, W.B. Saunders Company, 1988.

13. Bauerle O, Chrusch CA, Younes M. Mechanisms by which COPD affects exercise tolerance. Am J Respir Crit Care Med 1998; 157: 57-68.

14. O'Donnell DE, Lam M, Webb KA. Measurement of symptoms, lung hyperinflation, and endurance during exercise in chronic obstructive pulmonary disease. $\mathrm{Am}$ J Respir Crit Care Med 1998; 158: 1557-1565.

15. Dolmage TE, Goldstein RS. Repeatability of inspiratory capacity during incremental exercise in patients with severe COPD. Chest 2002; 121: 708-714.

16. Gibbons RJ, Balady GJ, Bricker JT, et al. ACC/AHA 2002 guideline update for exercise testing: summary article: a report of the American College of Cardiology/American Heart Association Task Force on Practice Guidelines (Committee to Update the 1997 Exercise Testing Guidelines). Circulation 2002; 106: 1883-1892.

17. O'Brien GM, Furukawa S, Kuzma AM, Cordova F, Criner GJ. Improvements in lung function, exercise, and quality of life in hypercapnic COPD patients after lung volume reduction surgery. Chest 1999; 115: 75-84.

18. Cordova F, O'Brien G, Furukawa S, Kuzma AM, Travaline J, Criner GJ. Stability of improvements in exercise performance and quality of life following bilateral lung volume reduction surgery in severe COPD. Chest 1997; 112: 907-915.

19. Oswald-Mammosser M, Kessler R, Massard G, Wihlm JM, Weitzenblum E, Lonsdorfer J. Effect of lung volume reduction surgery on gas exchange and pulmonary hemodynamics at rest and during exercise. Am J Respir Crit Care Med 1998; 158: 1020-1025.

20. Stammberger U, Bloch KE, Thurnheer R, Bingisser R, Weder W, Russi EW. Exercise performance and gas exchange after bilateral video-assisted thoracoscopic lung volume reduction for severe emphysema. Eur Respir J 1998; 12: 785-792.

21. Lando Y, Boiselle PM, Shade D, et al. Effect of lung volume reduction surgery on diaphragm length in severe chronic obstructive pulmonary disease. Am J Respir Crit Care Med 1999; 159: 796-805.

22. Leyenson V, Furukawa S, Kuzma AM, Cordova F, Travaline J, Criner GJ. Correlation of changes in quality of life after lung volume reduction surgery with changes in lung function, exercise, and gas exchange. Chest 2000; 118: 728735 .

23. Kaiwa Y, Kurokawa Y, Ando K, et al. Correlation of unilateral thoracoscopic lung volume reduction with improvement in lung function and exercise performance in patients with severe pulmonary emphysema. Surg Today 1999; 29: 718-723.

24. Gelb AF, Mckenna RJ Jr, Brenner M, Epstein JD, Zamel N. Lung function $5 \mathrm{yr}$ after lung volume reduction surgery for emphysema. Am J Respir Crit Care Med 2001; 163: 15621566.

25. Keller CA, Ruppel G, Hibbett A, Osterloh J, Naunheim KS. Thoracoscopic lung volume reduction surgery reduces dyspnea and improves exercise capacity in patients with emphysema. Am J Respir Crit Care Med 1997; 156: 60-67.

26. Benditt JO, Wood DE, McCool FD, Lewis S, Albert RK. Changes in breathing and ventilatory muscle recruitment patterns induced by lung volume reduction surgery. $\mathrm{Am}$ J Respir Crit Care Med 1997; 155: 279-284. 